\title{
POPULATION STUDY ARTICLE Backpack weight and back pain reduction: effect of an intervention in adolescents
}

\author{
Paloma Rodríguez-Oviedo ${ }^{1}$, María Isolina Santiago-Pérez ${ }^{2}$, Mónica Pérez-Ríos ${ }^{2,3,4}$, Dorotea Gómez-Fernández ${ }^{5}$, \\ Anselmo Fernández-Alonso ${ }^{5}$, Isabel Carreira-Núñez ${ }^{5}$, Pilar García-Pacios ${ }^{5}$ and Alberto Ruano-Ravina ${ }^{3,4}$
}

BACKGROUND: To assess if an educational intervention is effective to reduce backpack weight and back pain in schoolchildren. METHODS: We designed an intervention study in schoolchildren aged between 12 and 16 years aimed to reduce the weight of backpacks and back pain. The intervention was multifaceted, including an educational intervention with practical examples, advising on performing sports, postural habits, leaflets, stickers, and so on. The comparison group did not receive any intervention. RESULTS: A total of 1668 schoolchildren took part in the study. We observed a high prevalence of carrying heavy backpacks, with $66-80 \%$ of schoolchildren carrying backpacks surpassing $10 \%$ of their body weight. Back pain prevalence was $30 \%$. We observed that the intervention was significant in reducing the backpack weight in first-year schoolchildren but not in second-year. The intervention was also significant in reducing back pain in third-year schoolchildren but only in girls.

CONCLUSION: This study shows that an inexpensive intervention directed to reduce the backpack weight and back pain might have a positive effect in schoolchildren.

Pediatric Research (2018) 84:34-40; https://doi.org/10.1038/s41390-018-0013-0

\section{INTRODUCTION}

Back pain is a health problem that is on the rise among the adolescent population ${ }^{1}$ and can restrict activities of daily living to an appreciable extent. Lifestyle, coupled with little sports activity, is thought to contribute to loss of muscle tone in the back (coupled with lack of training of abdominal/core muscles). In many cases, these problems begin in childhood, ${ }^{2}$ when the adoption of inappropriate postures, both fixed ${ }^{3}$ and prolonged, ${ }^{4}$ is combined with the use of unergonomic school furniture whose measurements are not adapted to the anthropometric features of their users, ${ }^{5-7}$ and with the daily transport of heavy loads, e.g., backpacks full of books. $^{8}$ Experts recommend that the maximum weight which schoolchildren carry on their backs should not exceed $10 \%$ of the body weight of children at an age when they are still growing and developing. ${ }^{9}$ Furthermore, according to the 2011-2012 Spanish National Health Survey, $12 \%$ of schoolchildren aged $5-14$ years and $35 \%$ aged $15-24$ years are classified as sedentary. A total of $12 \%$ of teenagers and young adults aged 15-24 years have been medically diagnosed with chronic lower-back pain. ${ }^{10}$

Studies undertaken in various countries ${ }^{11}$ have shown that an individual with back pain in adolescence is more prone to develop back disorders and injuries at adult age, and similarly, that excess weight in backpacks may cause osteomuscular problems of the neck, shoulder, and back, such as scoliosis. ${ }^{12,13}$ This is more frequent in developed countries, where sedentarism and poor postural habits increase the incidence of back pain. ${ }^{14}$ Moreover, lumbago ranks first among musculoskeletal disorders, since it generates a high use of healthcare services and is the second leading cause of medical consultation after diseases of the upper respiratory tract. ${ }^{15}$
An earlier study conducted by our group prior to the intervention reported in this paper showed a direct relationship between school bag weight and back pain, as well as a high prevalence of back pain among schoolchildren in general, and girls in particular. ${ }^{16}$ As a continuation of this initial study, we designed an intervention targeted at reducing school bag weight and fostering habits that would reduce back pain in this population.

Accordingly, this study sought to assess the effectiveness of a corrective and preventive school-based intervention aimed at (a) reducing backpack weight in the 12- to 14-year age group; and, (b) reducing back pain in schoolchildren over the age of 14 years.

\section{METHODS}

Study scope

We carried out an intervention in the northern area of Lugo (Spain), which has a surface area of $1394 \mathrm{~km}^{2}$ and $\sim 75,000$ inhabitants distributed across 15 municipalities, mostly rural. The study population comprised all schoolchildren undergoing first to third compulsory secondary education (CSE) (Educación Secundaria Obligatoria). In Spain, mandatory high-school education comprises four academic years (CSE1, CSE2, CSE3, and CSE4) covering ages 12-16 years. In this study, CSE4 students were not included. The study was conducted across the four academic years from 2004/2005 to 2007/2008, and covered the area's 11 state-run high schools, which have an average of 2000 registered schoolchildren per year. Because the study had voluntary participation, was anonymous, and there was no intervention at an individual level, it was not necessary to have the approval of an Ethics

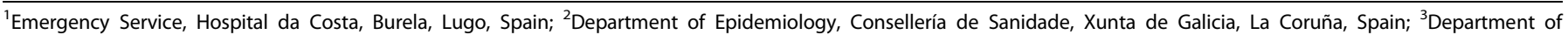

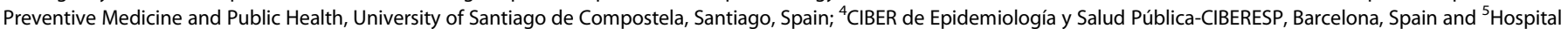
da Costa, Burela, Lugo, Spain

Correspondence: Alberto Ruano-Ravina (alberto.ruano@usc.es)

Received: 25 January 2018 Revised: 19 March 2018 Accepted: 20 March 2018

Published online: 23 May 2018 
Committee. Nevertheless, the protocol was approved by the Hospital da Costa Ethics Committee in 2005. Once the directors of the schools accepted to take part in the study, parents were informed about the study. Children took part only if parents authorized participation.

\section{Study phases}

At the beginning of every school year, two visits were made to the participating schools. Head teachers were contacted beforehand to present the project and arrange dates in coordination with their respective Directors of Studies. On the first visit, all schoolchildren enrolled in CSE academic year 1-3 (CSE1, CSE2, and CSE3) were given a consent form, containing information about the study and confidentiality of data, as required by the ISO/IEC 27002 standard (Personal Data Protection Act/Ley Orgánica sobre la protección de datos de carácter personal 15/1999), along with a questionnaire to be completed by their parents or guardians. The questionnaire was designed ad hoc in order to answer the objectives of the study. The instrument was tested in a pilot study in participants to ascertain the comprehensiveness of the questions and the validity of the response categories. Those items conducting to unreliable replies were rewritten or removed until the questionnaire items were easily understood by potential participants. On the second visit, we collected the completed questionnaires, and in the case of schoolchildren having signed consent forms, took their anthropometric measurements (weight and height) and weighed their backpacks. At the date of the first visit, pupils were not advised of the date of the second visit, so as to avoid introducing any bias in backpack weight.

\section{Intervention}

On the initial visit of every academic year (between September and December), except for the first academic year (2004-2005), we conducted an intervention targeted at CSE1 and CSE2 schoolchildren. The intervention was the same across all schools and consisted of a 1-h presentation for each classroom. The projected slides showed good and bad postural habits, correct and incorrect backpack positions, advisable maximum weight loads, and the consequences of overloading, as well as the benefits and virtues of sports activities and good nutrition. The intervention was administered by a team of four nurses previously trained on the contents. After the presentation, there was a demonstration of stretching exercises, encouraging students to repeat the exercises there and also at home routinely. During the physical education lesson, these exercises were reminded by the teacher. Posters were placed in corridors and classrooms of CSE1 and CSE2 during all academic years. Posters were replaced yearly during the present research and therefore all schoolchildren from CSE1 to CSE3 could see the posters. Posters showed images of correct backpack positioning, postural hygiene, sports activities, and sets of stretching exercises. Following the talk, stickers and information leaflets were handed out to be shared at home.

\section{Data collection}

Questionnaire. A 10-item questionnaire was drawn up containing the following variables: age; sex; five dichotomous variables (yes/ no): presence of injury or previously diagnosed back lesion (scoliosis, kyphosis, or other); absence or presence of back pain of more than 15 days' duration during the preceding year; whether a physician had been consulted in case of pain; improvement in pain during vacation periods; extracurricular activity; time devoted to sports and time devoted to sedentary activities (watching TV, laptop or video games, and studying) with categories: none, less than 1, between 1 and 2, and more than $2 \mathrm{~h}$ /day; transport used to travel to school (car, bus, and walking); and time spent carrying a backpack every day (less than half an hour, between $30 \mathrm{~min}$ and $1 \mathrm{~h}$, and more than $1 \mathrm{~h}$ ).

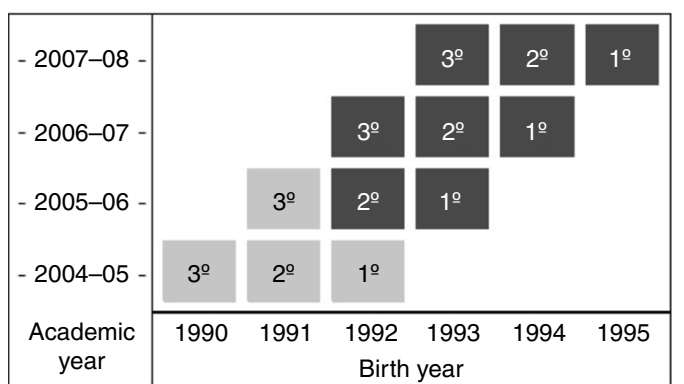

Fig. 1 Age-period cohort diagram to show control (gray) and intervention (dark) for each outcome. The X-axis represents birth year (cohort), Y-axis represents the school year, and the diagonal shows the academic year (age)

Measurements. Once the signed consent form had been collected, schoolchildren were weighed on a correctly calibrated, digital scale with a stadiometer attached (portable Tanita stadiometer to measure height $(\mathrm{cm})$ to the nearest $1 \mathrm{~cm}$; SECA Bellisima 841 scale to measure weight to the nearest $0.1 \mathrm{~kg}$ ). Two weightings were performed, with subjects wearing no bulky outer clothing and stripped of all items that might add extra weight (keys, mobile telephones, etc.). The first weighing was performed with the backpack positioned correctly and loaded with the material that the subject was carrying to school that day. At the second weighing, schoolchildren were weighed with no load. When the data of the two weighings were compared, the difference was used to calculate the weight of the load (the reason for adopting this procedure was to prevent possible errors in backpack weight, resulting from poor or defective positioning on the scale), which was then related on a percentage basis to the subject's anthropometric measures. Height was recorded by having schoolchildren stand erect, with their backs to the stadiometer, the posterior aspect of their heads against the blackboard, and their heels together. In all cases, weight and height readings were taken by the same person.

Control and intervention groups

Impact of the intervention on backpack weight. The control group was made up of CSE1 and CSE2 schoolchildren drawn from the $2004 / 2005$ academic year, and the intervention group was made up of CSE1 and CSE2 schoolchildren drawn from the three academic years from 2005/2006 to 2007/2008 (Fig. 1). CSE1 and CSE2 schoolchildren were analyzed separately because CSE1 schoolchildren during one academic year were mainly CSE2 schoolchildren during the next academic year.

Impact of the intervention on back pain. The control group was made up of CSE3 schoolchildren drawn from the 2004/2005 and $2005 / 2006$ academic years, and the intervention group by CSE3 schoolchildren from the 2006/2007 academic year (who received the intervention when they were in CSE2) and the 2007/ 2008 academic year (who received the intervention when they were in first and second-CSE academic years) (Fig. 1). No specific intervention was given to CSE3 schoolchildren.

Statistical analysis

For each academic year, the characteristics of the control and intervention groups were described by reference to the distribution of frequencies. Using data on CSE1 and CSE2 schoolchildren, we calculated mean backpack weight, both absolute and relative to body weight and the percentage of schoolchildren carrying a backpack weight exceeding $10 \%$ of their body weight. Data on CSE3 schoolchildren were then used to calculate the percentage of schoolchildren with back pain, with stratification by sex due to the differences found between boys and girls. When analyzing the 
Table 1. Characteristics of control and intervention groups of first and second grade of compulsory secondary education (CSE1-CSE2)

\begin{tabular}{|c|c|c|c|c|c|c|c|c|c|c|}
\hline & \multicolumn{5}{|c|}{ CSE1 } & \multicolumn{5}{|c|}{ CSE2 } \\
\hline & $n$ & $\%$ & $n$ & $\%$ & $p$-value & $N$ & $\%$ & $N$ & $\%$ & $p$-value \\
\hline \multicolumn{11}{|l|}{ Sex } \\
\hline Boys & 220 & 50.5 & 647 & 52.5 & 0.469 & 218 & 49.4 & 578 & 50.1 & 0.830 \\
\hline Girls & 216 & 49.5 & 585 & 47.5 & & 223 & 50.6 & 575 & 49.9 & \\
\hline 12-years old & 287 & 65.8 & 764 & 62.0 & 0.166 & - & - & - & - & \\
\hline 13-years old & 149 & 34.2 & 468 & 38.0 & & 278 & 63.0 & 698 & 60.5 & 0.359 \\
\hline 14-years old & - & - & - & - & & 163 & 37.0 & 455 & 39.5 & \\
\hline \multicolumn{11}{|c|}{ Body mass index categories } \\
\hline Underweight & 22 & 5.1 & 28 & 2.3 & 0.018 & 10 & 2.3 & 25 & 2.2 & 0.928 \\
\hline Two shoulder straps & 403 & 92.4 & 1179 & 95.7 & 0.008 & 405 & 91.8 & 1107 & 96.0 & $<0.001$ \\
\hline Other type & 33 & 7.6 & 53 & 4.3 & & 36 & 7.9 & 46 & 4.0 & \\
\hline \multicolumn{11}{|l|}{ Back lesion } \\
\hline No & 349 & 92.8 & 827 & 91.1 & 0.377 & 339 & 92.1 & 764 & 91.3 & 0.629 \\
\hline Yes & 27 & 7.2 & 81 & 8.9 & & 29 & 7.9 & 73 & 8.7 & \\
\hline \multicolumn{11}{|l|}{ Walking to school } \\
\hline No & 285 & 75.8 & 692 & 76.2 & 0.886 & 270 & 73.4 & 614 & 73.4 & 0.996 \\
\hline Yes & 91 & 24.2 & 216 & 23.8 & & 98 & 26.6 & 223 & 26.6 & \\
\hline
\end{tabular}

Table 2. Percentage of schoolchildren with backpack weight higher than $10 \%$ of their weight and $95 \%$ confidence interval, regarding schoolchildren characteristics

\begin{tabular}{|c|c|c|c|c|c|c|}
\hline & \multicolumn{3}{|l|}{ CSE1 } & \multicolumn{3}{|c|}{$\%(\mathrm{Cl} 95 \%)-\mathrm{CSE} 2$} \\
\hline Overall & $82.8(79.3-86.3)$ & $77.2(74.9-79.5)$ & 0.014 & $67.1(62.7-71.5)$ & $65.8(63.1-68.6)$ & 0.626 \\
\hline \multicolumn{7}{|l|}{ Sex } \\
\hline Boys & $81.4(76.2-86.5)$ & $75.1(71.7-78.4)$ & 0.057 & $61.5(55.0-67.9)$ & $62.3(58.3-66.2)$ & 0.832 \\
\hline Girls & $84.3(79.4-89.1)$ & $79.5(76.3-82.8)$ & 0.131 & $72.7(66.8-78.5)$ & $69.4(65.6-73.2)$ & 0.367 \\
\hline 13-years old & $78.5(71.9-85.1)$ & $74.4(70.4-78.3)$ & 0.304 & $70.5(65.1-75.9)$ & $69.3(65.9-72.8)$ & 0.721 \\
\hline 14-years old & - & - & - & $61.4(53.9-68.8)$ & $60.4(55.9-64.9)$ & 0.838 \\
\hline \multicolumn{7}{|l|}{ Overweight or obesity } \\
\hline No & $91.3(88.0-94.7)$ & $86.8(84.3-89.3)$ & 0.047 & $80.1(75.4-84.8)$ & $78.7(75.6-81.7)$ & 0.626 \\
\hline Yes & $67.9(60.7-75.2)$ & $63.7(59.6-67.9)$ & 0.335 & $45.5(37.9-53.1)$ & $45.8(41.2-50.4)$ & 0.943 \\
\hline
\end{tabular}

influence of body weight, we used the cutoff points proposed by Cole $^{17}$ to classify body mass index, which were transformed into two final categories (low or average weight and overweight or obesity).

For the indicators, "backpack weight exceeding 10\% of body weight" (in CSE1 and CSE2) and "back pain in the preceding year" (in CSE3), prevalence odds ratios (PORs) were calculated using logistic regression models and adjusting for schoolchildren's characteristics.

Means, prevalences, and PORs are shown with their 95\% confidence intervals (95\% Cls), and between-group comparisons were performed with Pearson's $X^{2}$ test in the case of categorical variables and the Mann-Whitney $U$-test in the case of continuous variables. 

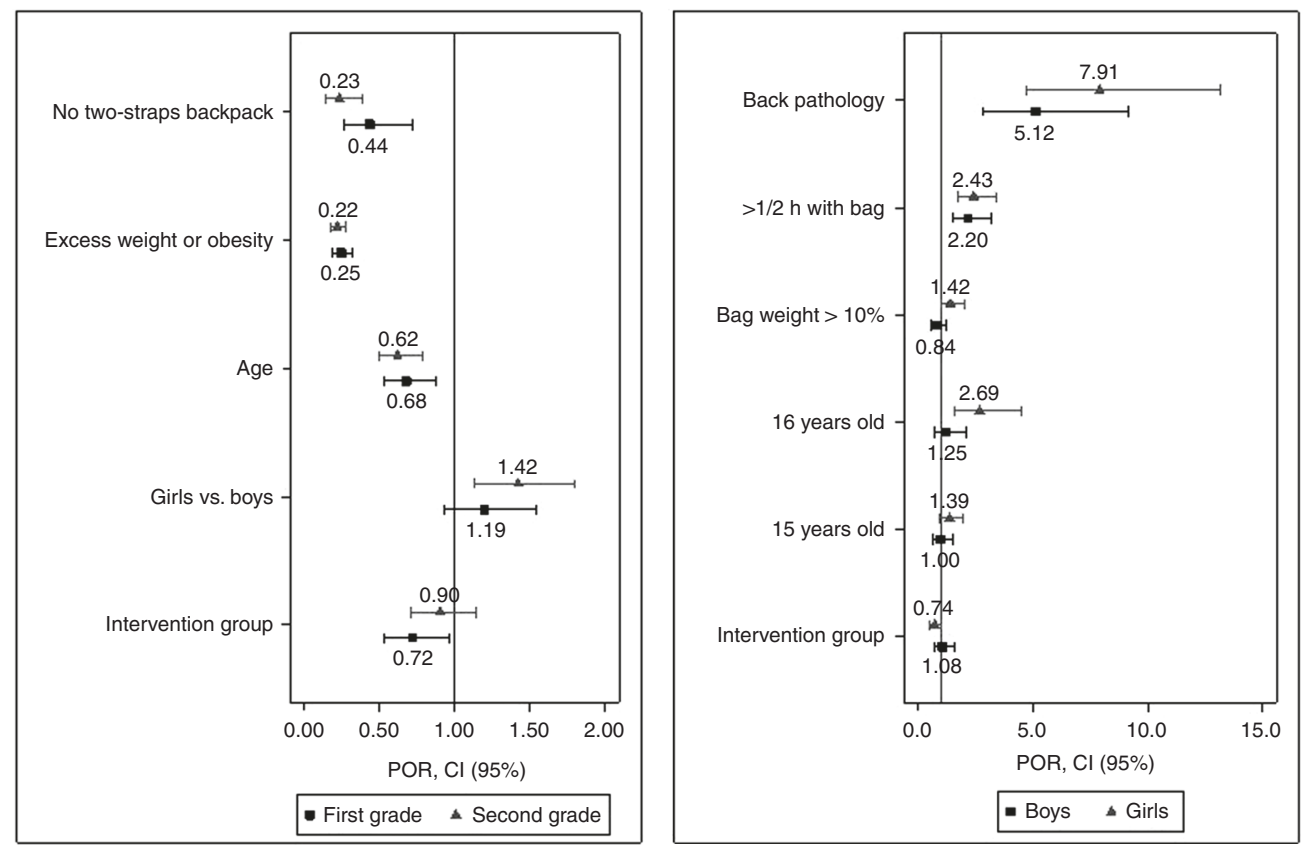

Fig. 2 Multivariate analysis results for the backpack weight in first and second years of CSE (left) and for back pain in the third year (right)

\section{RESULTS}

A total of 1668 CSE1 schoolchildren, 1594 CSE2 schoolchildren, and 1433 CSE3 schoolchildren participated in this study. Close to $80 \%$ of CSE1 schoolchildren and $66 \%$ of CSE2 schoolchildren carried a backpack with weights exceeding $10 \%$ of their body weight; among CSE3 schoolchildren, there was a $30 \%$ prevalence of back pain. A detailed flowchart of study participants is available as supplementary material of this paper (Supplemental Figure S1).

Effectiveness of the intervention to reduce backpack weight CSE1. The intervention covered 1668 CSE1 schoolchildren aged $12-13$ years, 436 in the control group (26\%), and 1,232 in the intervention group (74\%), with participation rates of $93 \%$ and $95 \%$, respectively; $52 \%$ of participating schoolchildren were males, $63 \%$ were 12 -years old, $40 \%$ presented overweight or obesity, and $95 \%$ used backpacks with two shoulder straps. Table 1 shows the characteristics of the control and intervention groups, which had a similar distribution by sex and age. In the intervention group, the prevalence of overweight or obesity was higher (36\% vs. $42 \%$ ), and there were more schoolchildren who used a standard (twostraps backpack) backpack (92\% vs. $96 \%$ ).

The mean weight carried by schoolchildren in their backpacks was $7.2 \mathrm{~kg}$ (95\% Cl: 7.1-7.3) and, on average, backpack weight accounted for $13.6 \%$ of body weight (95\% Cl: 13.4-13.8). The percentage of pupils who carried a backpack exceeding $10 \%$ of their body weight was $78.7 \%$ (95\% Cl: 76.7-80.6). Following the intervention, there was a significant reduction of $0.5 \mathrm{~kg}$ in mean backpack weight $(95 \% \mathrm{Cl}: 0.3-0.7, p<0.001)$, and $1.4 \%(95 \% \mathrm{Cl}$ : $0.9-1.8, p<0.001)$ in mean weight relative to body weight. The percentage of schoolchildren with a backpack weight exceeding $10 \%$ of their body weight was $82.8 \%$ (95\% Cl: $79.3-86.3)$ in the control group, and $77.2 \%$ (95\% Cl: 74.9-79.5) in the intervention group. The intervention had a significant effect on boys, on children aged 12, on schoolchildren who had low or average weight, and those who carried backpacks with two shoulder straps (Table 2). The crude POR of the intervention vs. the control group was 0.70 (95\% Cl: $0.53-0.93 ; p=0.014)$ and 0.72 (95\% Cl: $0.54-$ $0.97 ; p=0.032$ ) when adjusted for sex, age, overweight or obesity, and type of backpack (Fig. 2).
CSE2. The intervention covered 1594 CSE2 schoolchildren aged 13-14 years, 441 in the control group (28\%), and 1153 in the intervention group (72\%), with participation rates of $98 \%$ and $96 \%$, respectively; $50 \%$ of the schoolchildren participating were males, $61 \%$ were aged 13 years, 39\% presented with overweight or obesity, and $95 \%$ used a standard backpack. Although the control and intervention groups had a similar distribution by sex, age, and body mass index (BMI) category (Table 1), in the intervention group, there were more schoolchildren who used a standard backpack (92\% vs. $96 \%$ ).

The mean backpack weight carried by schoolchildren was $6.9 \mathrm{~kg}$ (95\% Cl: 6.8-7.0) and, on average, backpack weight accounted for $11.9 \%$ of body weight $(95 \% \mathrm{Cl}: 11.7-12.1)$. The percentage of schoolchildren who carried a backpack that weighed more than $10 \%$ of their body weight was $66.2 \%$ (95\% Cl: 63.9-68.5). Mean backpack weight, both absolute and relative to body weight, was slightly higher in the control group ( $7 \mathrm{vs} .6 .8 \mathrm{~kg}$ and $12.1 \%$ vs. $11.9 \%)$ but the difference was not significant. The percentage of children carrying backpack loads exceeding $10 \%$ of their body weight was also higher in the control group $[67.1 \%(95 \% \mathrm{Cl}$ : $62.7-71.5)$ vs. $65.8 \%(95 \% \mathrm{Cl}: 63.1-68.6)]$, without significant differences (Table 2). The crude POR of the intervention vs. the control group was 0.94 (95\% Cl: $0.75-1.19, p=0.626)$, and 0.90 (95\% Cl: $0.71-1.14 ; p=0.390)$ when adjusted for sex, age, overweight or obesity, and type of backpack (standard vs. other type) (Fig. 2).

Effectiveness of the intervention to reduce back pain

CSE3. The intervention covered 1433 CSE3 schoolchildren aged 14-16 years, 898 in the control group (63\%), and 535 in the intervention group (37\%), with participation rates of $73 \%$ and $54 \%$, respectively. The control and intervention groups had a similar distribution by sex ( $48 \%$ and $47 \%$ of males, respectively), but differed in age, with $49 \%$ of the control group vs. $56 \%$ of the intervention group being 14 years of age. They also differed in other characteristics (Table 3 ). In the intervention group, a higher percentage used a standard backpack ( $96 \%$ vs. $90 \%$ ), though $41 \%$ carried it for more than half an hour vs. $48 \%$ of the control group. The two groups had similar percentages of schoolchildren with back disorders. 
Table 3. Characteristics of control and intervention groups in the third grade of compulsory secondary education (CSE3)

\begin{tabular}{|c|c|c|c|c|c|}
\hline & \multicolumn{2}{|c|}{ Control } & \multicolumn{2}{|c|}{ Intervention } & \multirow[t]{2}{*}{$p$-value } \\
\hline & $n$ & $\%$ & $n$ & $\%$ & \\
\hline \multicolumn{6}{|l|}{ Sex } \\
\hline Boys & 439 & 48.4 & 251 & 46.9 & 0.623 \\
\hline Girls & 468 & 51.6 & 284 & 53.1 & \\
\hline \multicolumn{6}{|l|}{ Age } \\
\hline 14-years old & 443 & 48.8 & 300 & 56.1 & 0.024 \\
\hline 15-years old & 330 & 36.4 & 173 & 32.3 & \\
\hline 16-years old & 134 & 14.8 & 62 & 11.6 & \\
\hline \multicolumn{6}{|l|}{ Overweight or obesity } \\
\hline No & 602 & 66.4 & 342 & 63.9 & 0.345 \\
\hline Yes & 305 & 33.6 & 193 & 36.1 & \\
\hline \multicolumn{6}{|l|}{ School bag } \\
\hline Two shoulder straps & 819 & 90.3 & 514 & 96.1 & $<0.001$ \\
\hline Other type & 88 & 9.7 & 21 & 3.9 & \\
\hline \multicolumn{6}{|c|}{ Backpack weight $>10 \%$ of the body weight } \\
\hline No & 414 & 45.6 & 243 & 45.5 & 1.000 \\
\hline Yes & 493 & 54.4 & 291 & 54.5 & \\
\hline \multicolumn{6}{|c|}{ Time per day with the backpack on } \\
\hline Less than half an hour & 476 & 52.5 & 314 & 58.7 & 0.022 \\
\hline More than half an hour & 431 & 47.5 & 221 & 41.3 & \\
\hline \multicolumn{6}{|l|}{ Walking to school } \\
\hline No & 605 & 66.7 & 387 & 72.3 & 0.029 \\
\hline Yes & 302 & 33.3 & 148 & 27.7 & \\
\hline \multicolumn{6}{|l|}{ Performs sports regularly } \\
\hline No & 455 & 50.2 & 265 & 49.5 & 0.828 \\
\hline Yes & 452 & 49.8 & 270 & 50.5 & \\
\hline \multicolumn{6}{|l|}{ Time per day watching TV } \\
\hline Less than $1 \mathrm{~h}$ & 322 & 35.5 & 229 & 42.8 & 0.018 \\
\hline Between 1 and $2 \mathrm{~h}$ & 392 & 43.2 & 212 & 39.6 & \\
\hline More than $2 \mathrm{~h}$ & 193 & 21.3 & 94 & 17.6 & \\
\hline \multicolumn{6}{|c|}{ Time per day on the laptop or video games } \\
\hline None & 413 & 45.5 & 186 & 34.8 & $<0.001$ \\
\hline Less than $1 \mathrm{~h}$ & 276 & 30.4 & 177 & 33.1 & \\
\hline More than $1 \mathrm{~h}$ & 218 & 24.0 & 172 & 32.2 & \\
\hline \multicolumn{6}{|l|}{ Time per day studying } \\
\hline Less than $1 \mathrm{~h}$ & 233 & 25.7 & 124 & 23.2 & 0.318 \\
\hline Between 1 and $2 \mathrm{~h}$ & 312 & 34.4 & 204 & 38.1 & \\
\hline More than $2 \mathrm{~h}$ & 362 & 39.9 & 207 & 38.7 & \\
\hline \multicolumn{6}{|l|}{ Back lesion } \\
\hline No & 802 & 88.4 & 483 & 90.3 & 0.274 \\
\hline Yes & 105 & 11.4 & 52 & 9.7 & \\
\hline
\end{tabular}

Table 4 shows the prevalence of back pain for boys and girls separately and for each group, with a breakdown by schoolchildren's characteristics. The percentage of boys with back pain was $23.5 \%$, in both the control group (95\% Cl: 19.6-27.7) and the intervention group $(95 \% \mathrm{Cl}$ : 18.4-29.3), and there were no observable differences between the two groups when these results were stratified by schoolchildren's characteristics. Among girls, in contrast, there was a higher prevalence of back pain in the control group ( $39 \%$ vs. $30 \%, p=0.018$ ), something that was also observed in girls aged 15 years, those who did not have overweight or obesity, those who had standard backpacks that were heavier, as well as other characteristics linked to physical activity (Table 4).

The crude POR of having back pain in the intervention vs. the control group was 1.0 (95\% Cl: $0.69-1.44)$ in boys, and $0.68(95 \%$ $\mathrm{Cl}: 0.49-0.93)$ in girls. On adjusting for age, the time spent carrying the backpack per day, suffering from a back lesion, and having a backpack weight in excess of $10 \%$ of body weight, values of 1.07 (95\% Cl: $0.73-1.57)$ were obtained for boys, and $0.74(95 \% \mathrm{Cl}$ : $0.53-1.05 ; p=0.090$ ) for girls (Fig. 2).

\section{DISCUSSION}

These results show that an educational intervention targeting schoolchildren might reduce backpack weight, and that such interventions could also reduce the prevalence of back pain, though this latter outcome would seem to occur in girls rather than boys. Our results have to be considered with caution because this was not a randomized clinical trial and there is a risk of group contamination. Nevertheless, if this was the case, we should expect more relevant benefit than that observed. Another relevant result is that the percentage of schoolchildren who carry backpacks which exceed their body weight by more than $10 \%$ is very high, i.e., over $65 \%$, and varies slightly with CSE academic year. Furthermore, the prevalence of back pain is also high, i.e., $30 \%$. This is the study with the largest-sized sample to have been conducted on an educational intervention in schoolchildren to correct backpack weight.

The effect of the intervention on backpack weight proved to be statistically significant in CSE1 schoolchildren (average age 12 years) but not in CSE2 students. Among CSE1 schoolchildren, the prevalence of schoolchildren who carried a backpack that exceeded $10 \%$ of their body weight was reduced by just over $5 \%$. Likewise, the intervention was more effective among boys than girls, though the effect on both sexes was very similar. Among CSE2 schoolchildren, the intervention was not observed to have any effect. These results send out two relevant messages: first, that there can be effective interventions to reduce schoolchildren's backpack weight; and second, that not all points in time are appropriate for such interventions. According to these results, schoolchildren are more receptive when they are in the CSE1 (age 12 years) than when they are in CSE2. The fact that the control group was composed of schoolchildren drawn from the schools at a time when the intervention had not yet been implemented, rules out contamination of the control group. Similarly, the fact that at any given school, there may have been intervention groups and a control group should not have affected the results. One possible explanation for the lack of results in CSE2 schoolchildren may be that their age renders them less receptive to messages focusing on certain aspects of their lifestyle than are CSE1 schoolchildren, who have only just commenced a new educational cycle. A study undertaken in Mallorca on fifth- and sixth-grade primary school schoolchildren (15-16-years old) has confirmed that the interventions undertaken at the school on habits related to backpack use are effective, and that their effects are maintained at 6 months of follow-up. ${ }^{18}$

Another very relevant aspect is that the intervention implemented proved extremely inexpensive, since it consisted of talks and the distribution of informative material by a trained nurse. It is likely that, if the intervention had been somewhat more intense, the benefit obtained might have been greater in respect of this variable. An intervention on backpack weight can be considered a "proxy" of back pain, since previous studies have shown an association between backpack weight and manifestation of back pain. ${ }^{16}$

In terms of the intervention's effect on back pain, a differential effect was in evidence for boys and girls: whereas no effect was seen in boys, a relevant and statistically significant reduction in the prevalence of back pain was observed in girls. This reduction in the prevalence of back pain was evident in the analysis of other 
Tabla 4. Back pain prevalence in boys and girls in the third grade of compulsory secondary education (CSE3), regarding their characteristics

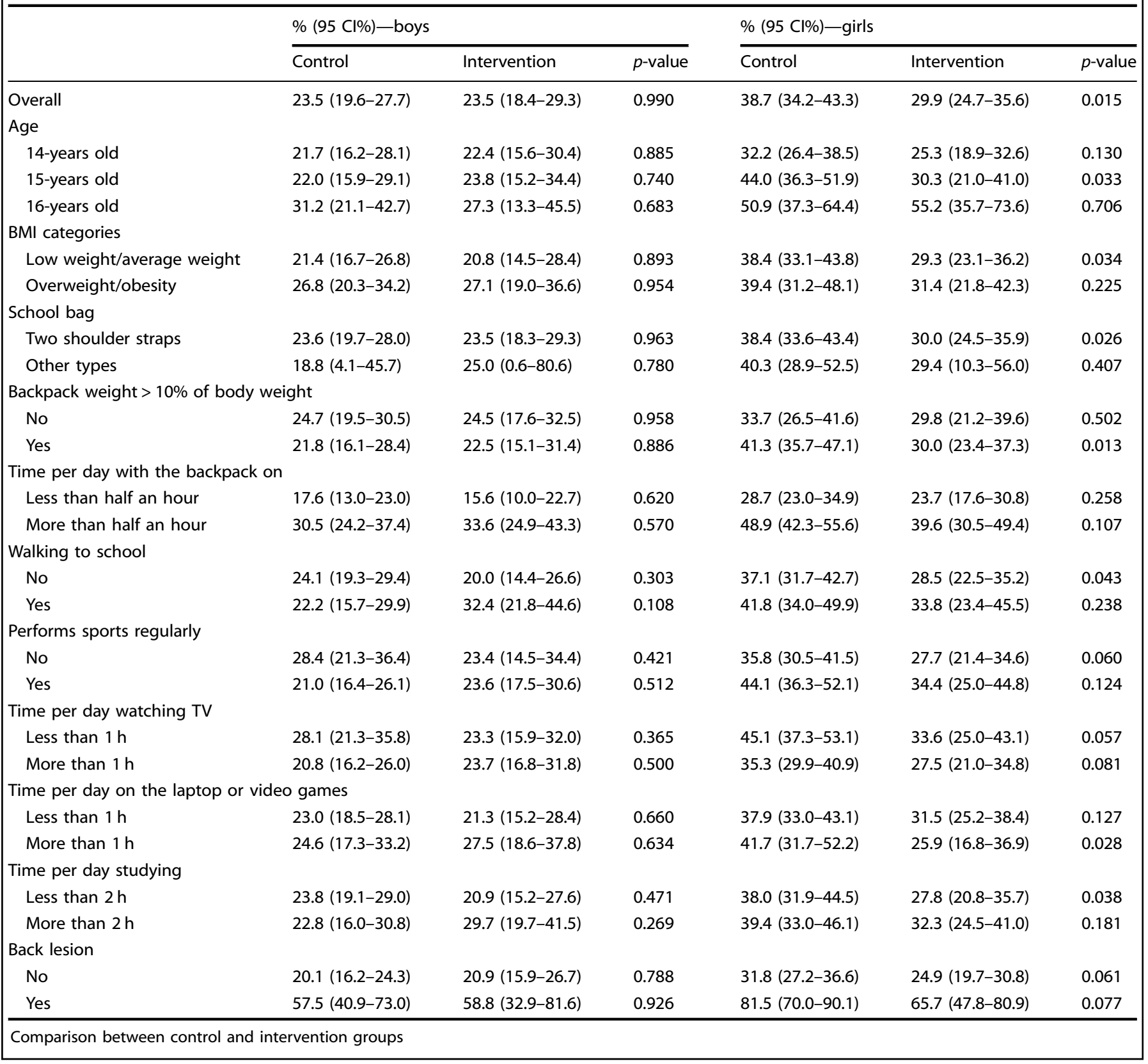

variables, e.g., there was a $14 \%$ reduction in prevalence among girls aged 15 years, which is a relevant figure from a clinical point of view.

In general, prevalence of back pain tends to be higher in girls than in boys. ${ }^{19,20}$ A possible explanation for this higher prevalence of back pain in girls could be that bone structure is consolidated at a different age than it is in boys, or alternatively, that part of the reported pain might be attributable to menstrual pain. This study showed that, in terms of the percentage of schoolchildren who carry backpacks which exceed $10 \%$ of their body weight, this is far higher in girls than in boys (65\% vs. $43 \%)$. Indeed, it is interesting to note that boys and girls carry approximately the same loads in their backpacks, with CSE3 boys and girls carrying backpack weights of 6.4 and $6.6 \mathrm{~kg}$, respectively, yet boys weigh more than do girls ( 69 vs. $60 \mathrm{~kg}$ ), so that the backpack-to-body weight ratio is actually higher in girls than in boys.
In addition to the intervention proposed in this study, a number of prevention activities to avoid excessive backpack weight were suggested. ${ }^{21}$ On the one hand, parents of younger schoolchildren should be involved in organizing and supervising backpack contents. $^{22}$ It is not reasonable that older (and therefore more judicious) schoolchildren should be carrying lighter schoolbags than their younger counterparts. In fact, it is entirely feasible that, most of the time, younger schoolchildren tend to carry unnecessary material in their schoolbags. On the other hand, the use of backpacks with wheels in our sample was purely anecdotal: their use should be encouraged, to avoid heavy loads being carried for a long time. Finally, it would be necessary to inform parents and children of the basic aspects of postural education and the importance of not carrying excessive weight. ${ }^{23}$ This task could be performed by nurses or educators directly at schools. Moreover, if this problem is to be remedied, the 
involvement of teachers is crucial, e.g., one multifaceted trial found no effect in the intervention group when backpack weight was reduced, possibly due to a scant $17 \%$ teacher participation. ${ }^{24}$ The arrival of new technologies may possibly replace books with weightless electronic devices, though this is not to be expected in the immediate future.

This study has a series of advantages, the most relevant of which was its design, i.e., its being a community intervention trial meant that it had a robust design for assessing the effectiveness of an intervention. Another advantage lay in the fact that no sampling was carried out: instead, the intervention included the entire sampling framework (universe) of schoolchildren who had agreed to participate and participation rate was high. This implies that there was no participation bias in the participants, and that the results are thus directly applicable to schoolchildren in the study area. We have not shown the results broken down by school because the area where the 11 included schools are settled has very similar characteristics, semiurban and coastal municipalities with no relevant cities. One last advantage linked to this was its large sample size, which implies that the results obtained are accurate, as can be seen from the confidence intervals of the different estimates.

Among the limitations of this study is one linked to its design, i.e., despite being an intervention study, it was undertaken sequentially rather than in parallel, and at any given school, there was a control group and an intervention group. There may be some risk of contamination of the control group, particularly from the placement of advertisements in the corridors of schools. Nevertheless, since the intervention comprised much more actions, we do not expect an important effect from this particular limitation. There is also some possibility of bias because some students might have modified the weight of the backpack after giving permission for participating in the study and before measuring backpack weight. We tried to minimize this without advertising the day the backpack was going to be measured. The intervention administered was not intensive (only at one point in time during the academic year). It will have to be seen whether interventions on, say, a quarterly basis, would have obtained a benefit of greater magnitude. Since the study was not designed from an ergonomic point of view, we do not have information regarding if students carrying standard backpacks (with two straps) used both straps or only one, or the height of the straps or even if the backpack had an additional strap to be fixed on the student's chest. The specific impact of these aspects on back pain should merit research in future studies. A final limitation is the variable, "presence of back pain", since this was self-reported and a subjective component in its assessment cannot therefore be ruled out, including the possibility of recall for long-time pain. In any event, researchers made every effort to ensure that this variable was reported in the same way in all participants.

In conclusion, this study has observed that reducing backpack weights by an average of $0.5 \mathrm{~kg}$ might be beneficial for schoolchildren. Moreover, this reduction and the intervention per se might have an influence on other trigger factors, by favoring activity, reducing sedentarism, and poor postural habits, whether in walking, sitting, or positioning the backpack correctly. The intervention itself was effective in reducing back pain, though only in girls. We cannot disregard the possibility of confounding despite having performed a multivariate logistic regression, so these results have to be managed carefully. The results obtained might have important socio-health implications, in that reducing back pain (with a high prevalence) in schoolchildren lessens their predisposition to suffer from lower-back disorders at adult age. It is also important to reduce the weight of backpacks and increase the use of backpacks with wheels when possible. The high prevalence of students ( $>65 \%$ ) carrying backpacks exceeding $10 \%$ of their body weight shows that poor emphasis is given in preventing this risk factor for back pain and back pathologies.

\section{AUTHOR CONTRIBUTIONS}

All authors have contributed equally to the study design. Statistical analysis has been performed by MISP and MPR. Questionnaire supervision was performed by P.R.-O. and A.R.-R. All authors have provided intellectual input to different drafts of the present manuscript. All authors have approved the submitted version of the manuscript and take public responsibility of its content.

\section{ADDITIONAL INFORMATION}

The online version of this article (https://doi.org/10.1038/s41390-018-0013-0) contains supplementary material, which is available to authorized users.

Competing interests: The authors declare no competing interests.

Publisher's note: Springer Nature remains neutral with regard to jurisdictional claims in published maps and institutional affiliations.

\section{REFERENCES}

1. Briggs, A. M. et al. Thoracic spine pain in the general population: prevalence, incidence and associated factors in children, adolescents and adults. A systematic review. BMC Musculoskelet. Disord. 10, 77 (2009).

2. Trevelyan, F. C. \& Legg, S. J. Back pain in school children-where to from here? Appl. Ergon. 37, 45-54 (2006).

3. Kovacs, F. M. et al. Risk factors for non-specific low back pain in schoolchildren and their parents: a population based study. Pain 103, 259-268 (2003).

4. Quintana, E. et al. Estudio de la postura sedente en una población infantil. Fisioterapia 26, 153-163 (2004).

5. Koskelo, R., Vuorikari, K. \& Hanninen, O. Sitting and standing postures are corrected by adjustable furniture with lowered muscle tension in high-school students. Ergonomics 50, 1643-1656 (2007).

6. Milanese, S. \& Grimmer, K. School furniture and the user population: an anthropometric perspective. Ergonomics 47, 416-426 (2004).

7. Skoffer, B. Low back pain in 15- to 16-year-old children in relation to school furniture and carrying of the school bag. Spine 32, E713-E717 (2007).

8. Mackenzie, W. G. et al. Backpacks in children. Clin. Orthop. Relat. Res. 409, 78-84 (2003).

9. Chow, D. H. et al. Postural perturbation and muscular response following sudden release during symmetric squat and stoop lifting. Ergonomics 48, 591-607 (2005).

10. Encuesta Nacional de Salud de España. Ministerio de Sanidad, Servicios Sociales e Igualdad e Instituto Nacional de Estadística 2011-2012.

11. van Gent, C. et al. The weight of schoolbags and the occurrence of neck, shoulder, and back pain in young adolescents. Spine 28, 916-921 (2003).

12. Hestbaek, L. et al. The course of low back pain from adolescence to adulthood: eight-year follow-up of 9600 twins. Spine 31, 468-472 (2006).

13. Negrini, S. \& Negrini, A. Postural effects of symmetrical and asymmetrical loads on the spines of schoolchildren. Scoliosis 2, 8 (2007).

14. Shehab, D. K. \& Al-Jarallah, K. F. Nonspecific low-back pain in Kuwaiti children and adolescents: associated factors. J. Adolesc. Health 36, 32-35 (2005).

15. Andersson, G. B. Epidemiological features of chronic low-back pain. Lancet 354, 581-585 (1999).

16. Rodriguez-Oviedo, P. et al. School children's backpacks, back pain and back pathologies. Arch. Dis. Child 97, 730-732 (2012).

17. Cole, T. J. \& Lobstein, T. Extended international (IOTF) body mass index cut-offs for thinness, overweight and obesity. Pediatr. Obes. 7, 284-294 (2012).

18. Vidal, J. et al. Effects of a postural education program on school backpack habits related to low back pain in children. Eur. Spine J. 22, 782-787 (2013).

19. Korovessis, P., Repantis, T. \& Baikousis, A. Factors affecting low back pain in adolescents. J. Spinal Disord. Tech. 23, 513-520 (2010).

20. Grimmer, K. \& Williams, M. Gender-age environmental associates of adolescent low back pain. Appl. Ergon. 31, 343-360 (2000).

21. Jayaratne, K., Jacobs, K. \& Fernando, D. Global healthy backpack initiatives. Work 41(Suppl 1), 5553-5557 (2012).

22. Javadivala, Z. et al. Awareness of parents about characteristics of a healthy school backpack. Health Promot Perspect. 2, 166-172 (2012).

23. Negrini, S. \& Carabalona, R. Backpacks on! Schoolchildren's perceptions of load, associations with back pain and factors determining the load. Spine 27, 187-195 (2002).

24. Negrini, S. et al. The backpack load in schoolchildren: clinical and social importance, and efficacy of a community-based educational intervention. A prospective controlled cohort study. Eura Med. 40, 185-190 (2004). 